OPEN ACCESS

Edited by:

Carsten Weiss,

Karlsruhe Institute of Technology (KIT), Germany

Reviewed by:

Peter Hoet,

KU Leuven, Belgium

Luciana Dini,

Sapienza University of Rome, Italy

*Correspondence:

Penny Nymark

penny.nymark@ki.se

Specialty section:

This article was submitted to

Nanotoxicology,

a section of the journal

Frontiers in Toxicology

Received: 14 January 2021

Accepted: 26 March 2021

Published: 29 April 2021

Citation:

Nymark P, Karlsson HL, Halappanavar S and Vogel U (2021)

Adverse Outcome Pathway

Development for Assessment of Lung

Carcinogenicity by Nanoparticles.

Front. Toxicol. 3:653386

doi: 10.3389/ftox.2021.653386

\section{Adverse Outcome Pathway Development for Assessment of Lung Carcinogenicity by Nanoparticles}

\author{
Penny Nymark ${ }^{1 *}$, Hanna L. Karlsson ${ }^{1}$, Sabina Halappanavar ${ }^{2}$ and Ulla Vogel ${ }^{3,4}$ \\ ${ }^{1}$ Institute of Environmental Medicine, Karolinska Institute, Stockholm, Sweden, ${ }^{2}$ Environmental Health Science and Research \\ Bureau, Health Canada, Ottawa, ON, Canada, ${ }^{3}$ National Research Centre for the Working Environment, Copenhagen, \\ Denmark, ${ }^{4}$ DTU Health Tech, Technical University of Denmark, Kgs. Lyngby, Denmark
}

Lung cancer, one of the most common and deadly forms of cancer, is in some cases associated with exposure to certain types of particles. With the rise of nanotechnology, there is concern that some engineered nanoparticles may be among such particles. In the absence of epidemiological evidence, assessment of nanoparticle carcinogenicity is currently performed on a time-consuming case-by-case basis, relying mainly on animal experiments. Non-animal alternatives exist, including a few validated cell-based methods accepted for regulatory risk assessment of nanoparticles. Furthermore, new approach methodologies (NAMs), focused on carcinogenic mechanisms and capable of handling the increasing numbers of nanoparticles, have been developed. However, such alternative methods are mainly applied as weight-of-evidence linked to generally required animal data, since challenges remain regarding interpretation of the results. These challenges may be more easily overcome by the novel Adverse Outcome Pathway (AOP) framework, which provides a basis for validation and uptake of alternative mechanism-focused methods in risk assessment. Here, we propose an AOP for lung cancer induced by nanosized foreign matter, anchored to a selection of 18 standardized methods and NAMs for in silico- and in vitro-based integrated assessment of lung carcinogenicity. The potential for further refinement of the AOP and its components is discussed in relation to available nanosafety knowledge and data. Overall, this perspective provides a basis for development of AOP-aligned alternative methods-based integrated testing strategies for assessment of nanoparticle-induced lung cancer.

Keywords: adverse outcome pathways, nanoparticles, genotoxicity, lung cancer, new approach methodologies

\section{INTRODUCTION}

A handful of nanosized particles, including welding fumes, diesel exhaust particles, carbon black, and titanium dioxide $\left(\mathrm{TiO}_{2}\right)$, have been classified as carcinogenic or possibly carcinogenic by the International Agency for Research on Cancer (IARC) (IARC, 2010, 2012a, 2014). Due to lack of epidemiological data for most engineered nanoparticles, insufficient understanding of how their physicochemical properties influence the disease process, and the need for onerous animal-based experimentation, it is not feasible to continue conventional types of risk assessments (Grosse et al., 2014; Catalán et al., 2017; Saber et al., 2019). Thus, the need for reformed safety assessment methods, founded on alternative non-animal approaches, is obvious. Alternative in silico and 
in vitro new approach methodologies (NAMs) already exist but are currently applied mainly to identify genotoxic mechanisms and provide plausibility to mutagenic endpoints observed in animals. Promising molecular biology tools such as highthroughput screening of perturbed key molecular players in toxicity pathways and high-content omics profiling are popular but hindered for uptake in safety assessment procedures due to the perceived risk of over-interpretation of the outcome without consideration of the broader biological context and the relevance for human carcinogenicity (IARC, 2014; Catalán et al., 2017).

The current understanding of genotoxic modes of action (MoAs) is fairly far developed and coupled to a battery of more or less standardized assays, including alternative non-animal methods, which have been specifically adapted for testing of nanoparticles (Dusinska et al., 2019). For example, assessment of primary genotoxicity, i.e., the capacity of an agent to produce genetic damage either directly by interacting with DNA or through release of genotoxic reactive oxygen species (ROS) and/or other agents, is supported by a variety of standardized in vitro assays, including specifications for applicability to nanoparticles (reviewed in Elespuru et al., 2018; Evans et al., 2019b). Other types of MoAs relevant to nanoparticles, such as secondary genotoxicity, induced by persistent tissue injury and chronic inflammation, has been difficult to address even using animal-based assays and standardized cell-based testing systems do not exist (Catalán et al., 2017). However, recent developments toward advanced physiologically relevant in vitro techniques capable of capturing chronic inflammation and secondary genotoxicity by nanoparticles provide solutions through use of co-cultures, conditioned media techniques, and diverse parallel assessments of pro-inflammatory mediators and genotoxicity (Åkerlund et al., 2019; Evans et al., 2019a; Halappanavar et al., 2020b; Kohl et al., 2020). Nevertheless, questions remain as to how to integrate and interpret the resulting data derived from isolated cells in the broader human-relevant context (Dusinska et al., 2017).

Adverse Outcome Pathways (AOPs) offer the much-needed biological context for in vitro-derived mechanistic data (Edwards et al., 2016). The AOP framework is conceptually highly similar to the classical MoA concept, which has governed genotoxicity research. However, in contrast to MoAs, which are bound to individual stressors, AOPs are stressor-agnostic and the information contained can be accessed, reused, updated, and applied to a variety of substances (Villeneuve et al., 2014; Sasaki et al., 2020). The AOP framework has emerged as a robust approach for anchoring mechanistic understanding to potential health effects in humans. It is expected to take risk assessment further along toward twenty-first century toxicity testing due to (i) its structured systematic approach including a repository and tools for sharing and collaborating (AOP-Wiki, www.aopwiki.org), (ii) its key focus on mechanistic information, and (iii) its governance by the OECD leading to broad support from large regulatory bodies (Leist et al., 2017). Further details on the framework and its benefits can be reviewed in Leist et al. (2017). The human relevance of the AOP-anchored mechanistic information becomes evident through meticulous integration of diverse types of data (including both legacy and new data) at various levels of biological organization, for the purpose of describing the most central molecular, cellular, organ, and individual level incidents that are connected to the final health effect. AOP development follows a row of central principles and is aligned with well-described guidance documents aiming for particular focus on the causality and essentiality in the chain of molecular initiating and key events (MIEs and KEs) leading to adverse outcome $(\mathrm{AO})$. In addition, key event relationships (KERs) allow for inclusion of information regarding the required threshold of perturbation for transitioning from one KE to the next (Coady et al., 2019). Thus, the framework also informs and facilitates the development of integrated testing and data interpretation strategies supporting regulatory decision making (Tollefsen et al., 2014; Ede et al., 2020).

Nanotoxicology has recently seen a rise in the development of field-relevant AOPs (Gerloff et al., 2017; Halappanavar et al., 2020b). Worth noting is that although AOPs are stressoragnostic, they may still be developed through case study approaches, whereby data integration focuses on one or several representative stressors known (or presumed) to be of concern for a specific AO (Gerloff et al., 2017; Halappanavar et al., 2019; Vinken, 2019). Focus within nanotoxicology has been directed toward one of the most relevant target organs for particle exposure, i.e., the lungs, and a set of six AOPs for diverse types of lung injury was recently published (Halappanavar et al., 2020b). In addition, the carcinogenicity of $\mathrm{TiO}_{2}$ was recently reviewed leading to a suggested $\mathrm{AOP}$ for $\mathrm{TiO}_{2}$-induced lung cancer (Braakhuis et al., 2020). The large body of published data and information on nanoparticles provides an extensive basis for further development and refinement of these AOPs (Karlsson et al., 2014; Gerloff et al., 2017; Elespuru et al., 2018; McCarrick et al., 2019).

Here, we describe a putative AOP for lung cancer associated with pulmonary deposition and retention of poorly soluble nanoparticles, covering aspects of both primary and secondary genotoxicity. The case study builds on information from diesel exhaust, carbon black, and $\mathrm{TiO}_{2}$ as representative stressors. In addition, a selected set of 18 in silico and in vitro assays applicable to nanoparticles and available for measurement and assessment of the KEs is aligned with the AOP. While full development of the AOP is beyond the scope of this perspective, we provide insight into the information required and the potential for further refinement of the currently proposed AOP backbone, including examples of available relevant data sets. Worth noting is that this perspective does not cover issues associated with high aspect ratio materials, as the case study stressors do not represent such materials, which have been handled elsewhere (Halappanavar et al., 2020b, 2021).

\section{DEVELOPMENT OF A PUTATIVE AOP FOR LUNG CANCER ASSOCIATED WITH NANOPARTICLES}

The particulate fraction of diesel exhaust is known to be required for carcinogenesis, since filtered exhaust does not cause lung cancer in rodents (Brightwell et al., 1989). Inhaled, 
nanosized particles deposit primarily in the alveolar region, where clearance is low, and lead to prolonged particle retention enabling particle-bio interaction (Oberdörster et al., 2005; Gaté et al., 2017). Interaction between particles and lung resident cell membrane components (Figure 1A, MIE) leads to inflammation (KE1A) which is proportional to the total deposited surface area (Schmid and Stoeger, 2016; Danielsen et al., 2020; Kokot et al., 2020). The persistence of particles results in long-lasting inflammation (Hougaard et al., 2010; Chézeau et al., 2018). Metabolic activity of pro-inflammatory cells induces formation of ROS, which may also be augmented by the surface reactivity of particles themselves (Jacobsen et al., 2008b; Bendtsen et al., 2020). The sustained inflammatory signaling and concomitant synthesis of reactive radicals, cause a chronic state of oxidantantioxidant imbalance and loss of protective mechanisms, potentially resulting in secondary genotoxicity (KE1B) (Evans et al., 2019a). Diesel exhaust consists of nanosized particles of inorganic and organic carbon with associated metal oxides and polyaromatic hydrocarbons (PAHs) (Taxell and Santonen, 2016; Bendtsen et al., 2020). Both the carbon core and solventextractable fractions containing PAHs are mutagenic in vivo and several metal (oxides) have been classified as (possibly) carcinogenic (IARC, 2006, 2012b; Hashimoto et al., 2007). It is possible that such genotoxic agents leach from the pulmonary deposited particles leading to activation of alternative AOPs associated with the formation of bulky DNA adducts and resulting in accumulation of mutations ( $\mathrm{Li}$ and Nel, 2006) as indicated by the alternative path in Figure 1A (in gray) (Sasaki et al., 2020). In addition, the insoluble carbon core generates particle-induced ROS leading to oxidative stress (KE1C) (Bendtsen et al., 2020; Gren et al., 2020). In a recent study of five diesel exhaust particles designed to differ in chemical composition, DNA strand breaks (KE2) in bronchoalveolar lavage cells were found to correlate with the ROS forming capacity of the particles (Bendtsen et al., 2020). Similarly, carbon black generates surface-dependent ROS, causing oxidative DNA damage (KE2) and mutagenicity (KE3) in vivo and in vitro (Jacobsen et al., 2008b). Finally, direct interactions between nanosized particles and DNA or the mitotic spindle are also possible, and the AOP features a direct link between the MIE and mutagenicity, i.e., KE3 (Buliaková et al., 2017; Patel et al., 2017).

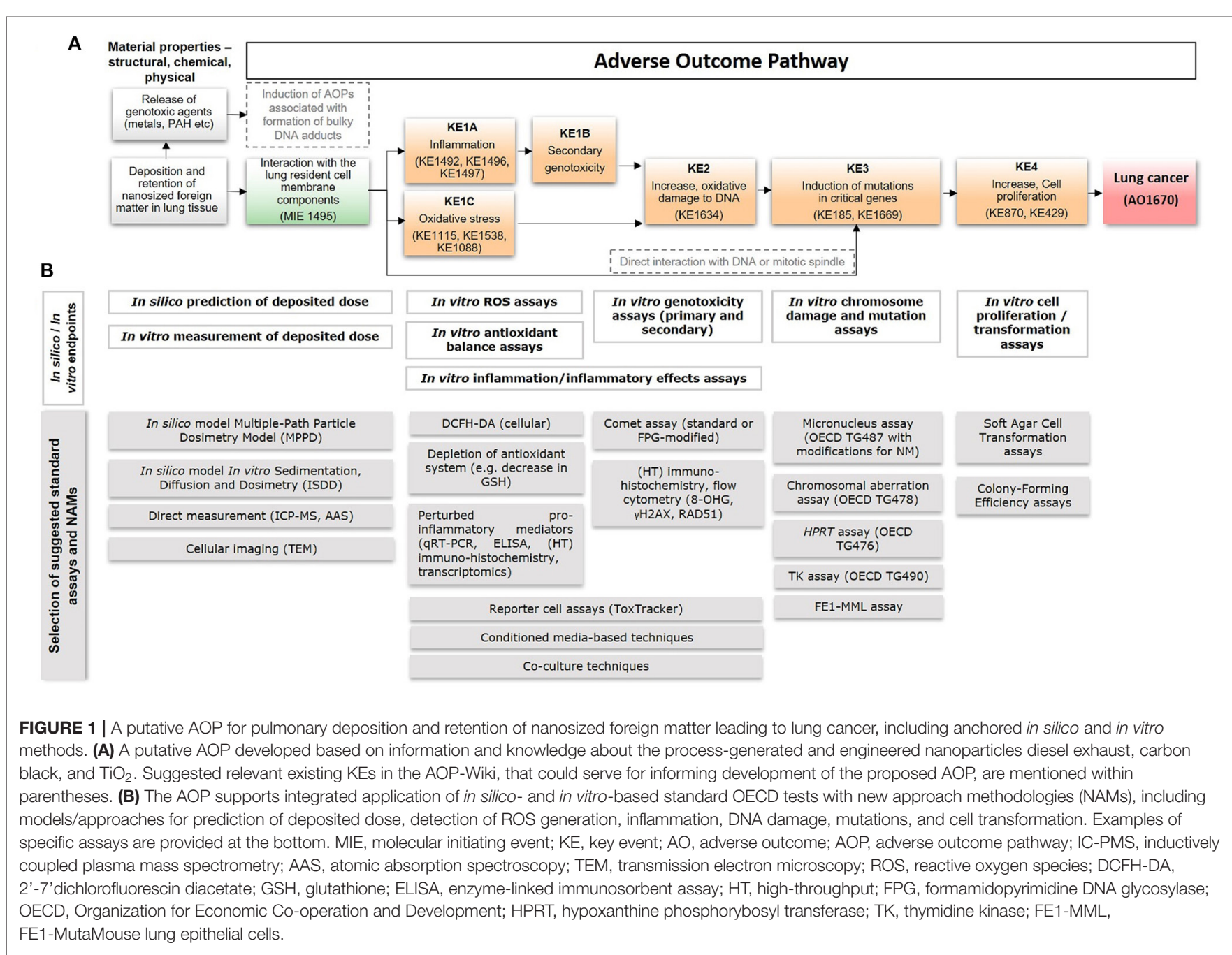


The genotoxic MoA is less clear for $\mathrm{TiO}_{2}$ nanoparticles. However, it is known that the carcinogenic potential of $\mathrm{TiO}_{2}$ is highly size-dependent and may include both particle-induced ROS generation and secondary genotoxicity (Liao et al., 2019; Saber et al., 2019). In fact, in 2-year inhalation studies in rats, carbon black, $\mathrm{TiO}_{2}$ nanoparticles, and diesel exhaust particles have shown highly similar carcinogenic potency (Saber et al., 2019) and the mutation frequency of carbon black and diesel exhaust particles were also very similar in vitro (Jacobsen et al., 2007, 2008a). This may be a coincidence, but it may also indicate that these low solubility particles share common pathways of carcinogenesis. Diesel exhaust, carbon black, and $\mathrm{TiO}_{2}$ nanoparticles have all also been shown to induce lung cell proliferation and transformation (KE4) in vitro and in vivo (Driscoll et al., 1996; Bayram et al., 2006; Medina-Reyes et al., 2015, 2019; Vales et al., 2015).

The MIE, KEs, and AO in the suggested AOP were aligned with relevant existing KEs in the AOP-Wiki, as well as selected evidence for their association with exposure to nanoparticles (Table 1). The table lists the original evidence from the three focus-stressors used to support the development of the AOP (as described above), as well as additional literature associated with metal (oxide) nanoparticles, including nickel (Ni), nickel oxide (NiO), silver, and gold, as well as silicon dioxide $\left(\mathrm{SiO}_{2}\right)$ nanoparticles.

\section{Factors Contributing to Particle-Induced Lung Carcinogenesis}

\section{Significance of the Overload Hypothesis}

Particle-induced lung cancer in rats has been subject to extensive scientific discussions (Institute IRS, 2000; Saber et al., 2019, 2020) due to the overload hypothesis, which suggests that particleinduced lung cancer observed in rats is an artifact caused by species-specific impaired particle clearance (Warheit et al., 2016). The hypothesis stems from observations that at very high lung burden, particle clearance is completely inhibited in rats, but not in mice (Elder et al., 2005). Furthermore, rats, but not mice, develop lung cancer following particleexposure (Heinrich et al., 1995). However, particle clearance was demonstrated in inhalation studies showing diesel exhaust, carbon black- and $\mathrm{TiO}_{2}$ nanoparticle-induced lung cancer (Heinrich et al., 1995). The particle clearance half-lives were determined to be 300-600 days (Heinrich et al., 1995), which may be comparable to the half-life of "several hundred days" for humans (Taxell and Santonen, 2016). Dose-response relationship between diesel exhaust exposure and lung cancer occurrence has been determined both in epidemiological studies and in chronic inhalation studies in rats (Heinrich et al., 1995; Ge et al., 2020). Epidemiological evidence indicates that occupational exposure to $1 \mu \mathrm{g} / \mathrm{m}^{3}$ diesel exhaust measured as elemental carbon during a 45-year work life, is associated with 40-170 excess lung cancer cases per 100,000 exposed. Thus, based on epidemiological evidence, lung cancer occurs in humans at exposure levels (1$10 \mu \mathrm{g} / \mathrm{m}^{3}$ ), where particle overload cannot be a problem. In comparison, 1.3 excess lung cancer cases per 100,000 exposed are expected based on chronic inhalation studies in rats (Vermeulen et al., 2014; Saber et al., 2019; Ge et al., 2020). Hence, when comparing risk estimates based on epidemiological studies with those based on inhalation studies in rats, diesel exhaust appears most potent in the epidemiological studies, indicating that chronic inhalation studies of particles in rats are predictive of human cancer risk, at least with regard to diesel exhaust particles (Saber et al., 2019). The available data on the carcinogenic potency of diesel in both epidemiological studies and animal studies, in addition to knowledge on the potential MoAs in relation to carcinogenicity, makes diesel exhaust a suitable model stressor in the current AOP-development case study.

For $\mathrm{TiO}_{2}$, the overload hypothesis in humans remains unsolved due to lack of epidemiological data, as described in the recent review by Braakhuis et al. (2020). Since particle size and hence deposited surface area is a strong determinant of the carcinogenic potency of $\mathrm{TiO}_{2}$ particles in animal studies, the lack of information on particle size distribution in available epidemiological studies of $\mathrm{TiO}_{2}$ exposure hampers comparison of the carcinogenic potency of these particle in rats and humans (Heinrich et al., 1995).

Taken together, the AOP includes consideration of "Deposition and retention of nanoparticles in the lung" (Figure 1A) and anchors to methods allowing for dosedetermination (Figure 1B, see further details on methods below in section Assessment of deposited dose). However, the overload hypothesis is then not specifically considered in the AOP, since literature on diesel exhaust supports the notion that lung cancer in humans is present at lower doses than at which overload would be.

\section{Significance of Inflammation and Secondary Genotoxicity}

Immune and pro-inflammatory responses are a critical component of host defense (Shacter and Weitzman, 2002). In lungs, the interaction of stressors with resident cells leads to cell injury resulting in release of cellular content such as danger associated molecular patterns or alarmins, including cellular debris, cytokines, and chemokines. Alarmins bind to cell surface receptors and activate inflammatory pathways, such as secretion of a variety of cytokines and chemokines, which in turn signal recruitment of neutrophils, macrophages, and other immune cells to the site of infection or injury (Villeneuve et al., 2018; Halappanavar et al., 2019). The primary purpose of inflammation is to resolve infection and promote healing. However, repeated exposure or tissue persistence of the noxious substance results in unresolved inflammation, leading to tissue injury and chronicity. Chronic inflammation precedes tissue dysfunction and disease progression (Halappanavar et al., 2020a). The immune cells and the pro-inflammatory mediators involved in the inflammatory process are indistinguishable in acute and chronic inflammation, and it is rather the lack of resolution of inflammation, leading to injury, that is potentially causative of cancer. Soluble mediators such as oxidants, arachidonic acid, cytokines, and chemokines released as result of the metabolic activity of immune cells such as neutrophils and macrophages, can lead to oxidative stress, oxidative DNA damage, and cellular proliferation. 
TABLE 1 | MIE, KEs, and AO in the suggested putative AOP aligned with existing KEs available in the AOP-Wiki (https://aopwiki.org/) and selected evidence from nanotoxicology literature [with focus on the case study stressors and metal (oxide) nanoparticles].

\begin{tabular}{|c|c|c|c|}
\hline $\begin{array}{l}\text { KE in newly } \\
\text { suggested AOP }\end{array}$ & $\begin{array}{l}\text { Existing associated KE in the } \\
\text { AOP-Wiki }\end{array}$ & $\begin{array}{l}\text { Relevant evidence from studies on } \\
\text { nanoparticles }\end{array}$ & References \\
\hline MIE & $\begin{array}{l}\text { KE1495 interaction with the lung } \\
\text { resident cell membrane components }\end{array}$ & $\begin{array}{l}\text { Retained nanoparticles, including } \mathrm{TiO}_{2} \text {, } \\
\text { carbonaceous, and a number of metal (oxide) } \\
\text { nanoparticles interact with lung resident cell } \\
\text { membranes and receptors (e.g., through } \\
\text { toll-like receptors) }\end{array}$ & $\begin{array}{l}\text { Chen et al., 2013; Labib et al., 2016; } \\
\text { Nikota et al., 2016; Schmid and } \\
\text { Stoeger, 2016; Danielsen et al., 2020; } \\
\text { Gliga et al., 2020; Kokot et al., 2020; } \\
\text { Vasilichin et al., } 2020\end{array}$ \\
\hline
\end{tabular}

KE1496 increased, secretion of proinflammatory and profibrotic mediators

KE1497 increased, recruitment of inflammatory cells

Inflammation-driven genotoxicity observed in bronchial epithelial cells for $\mathrm{TiO}_{2}, \mathrm{SPIONs}$, and $\mathrm{NiO}$ nanoparticles

A number of nanoparticles, including $\mathrm{TiO}_{2}$ and $\mathrm{SiO}_{2}$, as well as the insoluble carbon core of diesel exhaust generates ROS leading to oxidative stress in lung cells both in vitro and in vivo

KE1538 decreased protection against oxidative stress

KE1088 increased, oxidative stress

KE2 KE1634 increase, oxidative damage to DNA

KE3

KE185 increase, mutations

KE1669 increased, DNA damage, and mutation

KE4 KE870 increase, cell proliferation

KE429 cellular proliferation and clonal expansion of mutant cells (pre-neoplastic foci), alteration of cellular growth homeostasis
Diesel exhaust nanoparticles, $\mathrm{TiO}_{2}$, and a number of other metal (oxide) nanoparticles, such as silver and gold, cause oxidative damage to DNA in lung cells both in vitro and in vivo

Diesel exhaust nanoparticles, carbon black, $\mathrm{TiO}_{2}$, and a number of other metal (oxide) nanoparticles, such as silver, $\mathrm{Ni}$, and $\mathrm{NiO}$, induce gene mutations, formation of micronuclei, and chromosomal aberrations in lung cells

Diesel exhaust, $\mathrm{TiO}_{2}$ and carbon black nanoparticles induce lung cell proliferation, and a number of other metal (oxide) nanoparticles, such as silver, as well as $\mathrm{SiO}_{2}$, have been shown to induce lung cell transformation

Diesel exhaust is linked with dose-dependent increase in the risk for lung cancer in humans. Diesel exhaust, $\mathrm{TiO}_{2}$, and carbon black are all also coupled to highly similar rates of dose-dependent induction of lung cancer in vivo
Åkerlund et al., 2019; Evans et al., 2019a

Jacobsen et al., 2008b; Bendtsen et al., 2020; Gren et al., 2020;

Karkossa et al., 2021

Karlsson et al., 2014; Golbamaki et al., 2015; Lebedová et al., 2018; Bendtsen et al., 2020; Ling et al., 2020

Jacobsen et al., 2007, 2008a; Golbamaki et al., 2015; Åkerlund et al., 2018; Lebedová et al., 2018; Ling et al., 2020

Driscoll et al., 1996; Bayram et al., 2006; Medina-Reyes et al., 2015, 2019; Vales et al., 2015; Fontana et al., 2017; Gliga et al., 2018

Mauderly et al., 1994; Heinrich et al., 1995; Vermeulen et al., 2014; Ge et al., 2020 
Chronic inflammation involving pathogenic infections, chemicals, and non-soluble particles is known to lead to tissue cancer in animal models (reviewed in Shacter and Weitzman, 2002). In addition, particle deposition and persistence, lung inflammation, and increased risk of developing cancer has been observed in workers exposed to coal dust, carbon black, diesel exhaust, and crystalline silica (Kuempel and Ruder, 2009). Poorly soluble low-toxicity particles such as $\mathrm{TiO}_{2}$ are suggested to induce cancer via secondary genotoxicity mechanisms involving oxidative stress, chronic inflammation, and cell proliferation (Braakhuis et al., 2020). Furthermore, some engineered nanoparticles induce fibrosis of lungs, which is also linked to initiation of carcinogenesis (Elder et al., 2005; Zhou et al., 2020). Thus, although it has been difficult to find evidence directly supporting the role of inflammation in nanomaterial-induced carcinogenic processes, the existing literature is suggestive of such links. These links have not to date been described in the AOP-Wiki.

\section{AOP-Anchored Tests for Carcinogenicity Assessment by Nanoparticles}

To provide a basis for the development of integrated testing strategies for the assessment of lung carcinogenicity by nanoparticles, we provide an overview of 18 in silico and in vitro standard methods and NAMs applicable to and in some cases already frequently used for nanoparticles, and anchor them to the putative AOP described above (Figure 1B).

\section{Assessment of Deposited Dose}

Dose is a key factor for toxicological assessment including for assessment of human relevance, i.e., allowing for comparisons between human and in vitro exposure. Exposure via inhalation is typically reported in terms of particle concentration in air $\left(\mathrm{mg} / \mathrm{m}^{3}\right)$ whereas in vitro studies often report mass of nanoparticles per unit volume $(\mu \mathrm{g} / \mathrm{ml})$. In order to enable comparisons between models, it is helpful to consider cellular target dose as compared to tissue burden. The nominal concentration in the medium of in vitro studies can differ substantially from the cell dose since different nanoparticle characteristics affect their ability to reach the cells at the bottom of the culture dish (Teeguarden et al., 2007). For metal (oxide) nanoparticles, the cellular dose can be measured quantitatively using e.g., Inductively Coupled Plasma Mass Spectrometry (ICP-MS) or Atomic Absorption Spectroscopy (AAS), or qualitatively through cellular imaging using Transmission Electron Microscopy (TEM). For ICP-MS and AAS, however, it may be difficult to distinguish between nanoparticles taken up by the cells and those simply attached to the cell membrane. Another limitation is their inability in general to distinguish between the nanoparticle itself and ions released from the nanoparticles. The delivered dose can alternatively be estimated by modeling, e.g., using the in vitro Sedimentation, Diffusion and Dosimetry (ISDD) model to estimate the movement of particles to the cells (Hinderliter et al., 2010). Similarly, estimations of tissue deposition of airborne nanoparticles with different characteristics can be performed with the Multiple-Path Particle Deposition model (MPPD), which calculates the deposition and clearance of mono- and polydisperse aerosols containing particles ranging in size from ultrafine/nanosized $(100 \mathrm{~nm})$ to coarse $(20 \mu \mathrm{m})$ in the respiratory tract of humans (Miller et al., 2016). Overall, these methods are useful for assessment and estimation of the deposited dose both in vitro and in humans to allow for comparisons and identification of required thresholds of perturbation in results obtained with assays anchored to downstream components of the AOP (Figure 1A).

\section{Assessment of Oxidative Stress and Inflammation}

Phagocytic cells may internalize deposited particles leading to respiratory burst and release of ROS, leading to oxidative stress and inflammation (KE1C and KE1A, Figure 1A). The fluorometric assay relying on the intracellular oxidation of 2'7'dichlorofluorescin diacetate (DCFH-DA) is commonly used to detect ROS release in cells in vitro (Decan et al., 2016). In addition, lipid peroxidation, protein oxidation, and protein carbonylation can be measured as indicative of oxidative stress using proteomics techniques (Riebeling et al., 2016). Other approaches include measurement of intracellular glutathione levels using the ThiolTracker ${ }^{\mathrm{TM}}$ Violet assay (Decan et al., 2016), glutathionylation of proteins, or expression assessment of relevant genes and proteins associated with antioxidant pathways, e.g., using reporter cell lines such as the ToxTracker system (Karlsson et al., 2014; Riebeling et al., 2016).

The selection of pro-inflammatory mediators for investigation differs and is dependent on the expertise of the lab, cell types studied and availability of the specific antibodies. Most routine assays involve measuring the abundance of cytokine mRNA in a given sample using targeted or array-based quantitative (q)RT-PCR. In addition, novel high-throughput and targeted transcriptomic techniques are increasingly becoming available for assessment of transcriptional changes in relevant gene sets and biological pathways (Collins et al., 2017). The protein levels of cytokines and their activation state can also be measured using targeted Western blot assays and ELISA assays. The latter allows quantitative measurement of antigens in biological samples. Both mRNA- and protein-based methods are readily applicable to in vitro cell culture models, where cell culture supernatants or whole cell homogenates are useful, and allow for high-throughput, simultaneous assessment of multiple proinflammatory mediators in a single setting (Husain et al., 2015). Lastly, immunohistochemistry can be used to detect specific immune cell types producing pro-inflammatory mediators and its downstream effectors in any given tissue (Costa et al., 2018). However, the technique is not quantitative and the sensitivity depends on the specificity of the antibodies employed (Amsen et al., 2009). Some of the most commonly assessed proinflammatory mediators include IL-6, IL-8, TNF $\alpha$, IL-1 $\beta$, NF$\kappa \mathrm{B}$, and IFN $\gamma$ (Nymark et al., 2018a). However, the relative predictive efficiency and sensitivity are not validated and may vary from one test system to another. Moreover, most proinflammatory mediators play a pleotropic role and their activities in carcinogenicity still require further research (Gomes et al., 2014).

Recruitment of pro-inflammatory cells is currently not possible to assess in vitro. However, with the development 
of more advanced model systems, such as conditioned media approaches, co-cultures, and ultimately organotypic cultures it may become feasible (Kohl et al., 2020).

\section{Assessment of DNA Damage and Mutagenicity, Including Secondary Genotoxicity}

In vitro assessment of genotoxicity can be divided into two types of assays; (i) assessment of repairable DNA damage or related DNA repair mechanisms, and (ii) assessment of irreparable DNA damage, i.e., inheritable chromosome damage and mutations. Here, we refer to the former as genotoxicity assays, which are anchored with KE1B and KE2 (Figure 1A), and the latter as chromosome damage and mutation assays, anchored with KE3. Detailed definition of genotoxicity and mutagenicity can be reviewed in Catalán et al. (2017).

The comet assay is one of the most commonly used methods for assessing genotoxicity of nanoparticles (Magdolenova et al., 2014; Golbamaki et al., 2015; Elespuru et al., 2018). Overall, the assay is generally applicable to nanoparticles but with some precaution and awareness (Karlsson et al., 2015). For example, photo-catalytically active nanoparticles, e.g., $\mathrm{TiO}_{2}$ may cause false positives in the presence of light. In addition, DNA damage formed during the assay performance has also been reported for copper oxide $(\mathrm{CuO})$ nanoparticles, but the extent to which it interferes with the assay remains to be elucidated (Karlsson et al., 2015). The comet assay can also be combined with enzymes, most commonly FPG (formamidopyrimidine DNA glycosylase), allowing for detection of oxidatively damaged DNA (Magdolenova et al., 2014). Recent developments of the comet assay has resulted in higher throughput approach, including automated scoring of mini-gel comets (Jackson et al., 2013; Brunborg et al., 2014; Collins et al., 2017). Other high-throughput assays used for the indication of (still repairable) genotoxicity include e.g., flow cytometry or immunohistochemistry to detect the formation of phosphorylated histone $\mathrm{H} 2 \mathrm{AX}(\gamma-\mathrm{H} 2 \mathrm{AX})$, indicating initiation of DNA repair mechanisms targeting double strand breaks (Nelson et al., 2017; Åkerlund et al., 2018). The ToxTracker reporter assay is also, in addition to oxidative stress mentioned above, capable of assessing genotoxicity, protein folding and p53-related cellular stress based on the transcriptional activation of a set of six key genes (Hendriks et al., 2016). Recent results have demonstrated the applicability of the assay to 33 different nanoparticles, showing a great diversity in activation and magnitude of induction of the various reporters (Cappellini et al., 2020; McCarrick et al., 2020). Thus, these assays have been anchored with KE2 (Figure 1A). Both KE1B and KE2 are also covered by newly developed methods including conditioned media approaches, whereby cells are treated with media from nanomaterial-exposed immune cells, or co-cultures of e.g., macrophages and epithelial cells, as described previously in relation to testing superparamagnetic iron oxide (SPION) and NiO nanoparticles (Åkerlund et al., 2019; Evans et al., 2019b).

With regard to mutagenicity and chromosomal aberration assays, these include another of the most commonly used assay for nanoparticles, i.e., the micronucleus assay [OECD test guideline (TG) 487; Magdolenova et al., 2014; Golbamaki et al., 2015; Elespuru et al., 2018]. Modifications of the assay toward applicability to nanoparticles are included in the standardized guidelines for nanoparticle-application (Elespuru et al., 2018). The assay can be coupled to flow cytometry to increase throughput for scoring of micronuclei (Di Bucchianico et al., 2017; Lebedová et al., 2018). In addition, the Chromosomal Aberration Assay (OECD TG478) is applicable to nanoparticles (Elespuru et al., 2018). Other standardized assays include a variety of mammalian cell mutation assays; the thymidine kinase (TK) assay (OECD TG 490), the Hprt (hypoxanthine-guanine phosphoribosyltransferase) assay (OECD TG 476), and the cII loci assay (FE1-MML) (Jacobsen et al., 2007, 2008a; Decan et al., 2016; Åkerlund et al., 2018; Kohl et al., 2020). These have all been anchored with KE3 in the putative AOP (Figure 1A).

\section{Assessment of Increased Cell Proliferation and Carcinogenicity}

Finally, assessment of cell transformation and increased cell proliferation, as a result of the upstream events, is coupled to cell morphological changes, as shown for e.g., cobalt nanoparticles (Ponti et al., 2009), or the ability of exposed cells to grow in soft agar (Kohl et al., 2020). This is a carcinogenic feature of cells that may be particularly relevant after low dose long-term studies, as suggested for e.g., $\mathrm{TiO}_{2}$ nanoparticles, and thus anchored with KE4 (Figure 1A) (Vales et al., 2015). The latest developments of advanced organotypic and $3 \mathrm{D}$ models can also be expected to support assessment of the carcinogenic potential of nanoparticles in line with the AO (Kohl et al., 2020).

\section{DISCUSSION}

Assessment of carcinogenicity is coupled to a well-developed set of standardized in vitro-based genotoxicity and mutagenicity alternatives that enable assessment of direct-acting carcinogens (Corvi and Madia, 2017). Some of these assays have been or are being evaluated and modified accordingly to be applicable to nanomaterial testing (Karlsson et al., 2014; Nelson et al., 2017). Nevertheless, challenges remain regarding assessment of e.g., secondary genotoxicity MoAs induced by nanoparticles. In addition, there is a need to improve the applicability of new mechanism-focused methods for genotoxicity testing in safety assessment practices. This perspective provides an overview of a putative AOP describing deposition and retention of nanosized foreign matter leading to lung cancer, building on knowledge, and understanding of carcinogenesis induced by diesel exhaust, carbon black, and $\mathrm{TiO}_{2}$ nanoparticles. The AOP is aligned with a selected set of in silico- and in vitro-based standard and new assays which support integrated assessment and interpretation of the putative MIEs and KEs, based on currently available data on nanoparticles (Halappanavar et al., 2020b). Overall, the putative AOP presented here extends on a recently proposed AOP operative for assessment of $\mathrm{TiO}_{2}$ carcinogenicity in rats, and opens for the possibility to iteratively build further on the KE descriptions (Braakhuis et al., 2020).

The nanosafety community has over the past decade focused extensively on enabling harmonized data management of the widely diverse data types generated within the field, and has recently led to the establishment of the Nanosafety Data 
Interface (https://search.data.enanomapper.net/) which provides findable, accessible, interoperable, and reusable (FAIR) data from several European projects (Jeliazkova et al., 2015, in press). Such available data support recently proposed data integration strategies allowing for validation and threshold estimation of the KEs as well as further development of KERs in the suggested AOP (Nymark et al., 2018b; Halappanavar et al., 2021). Eventually, the added value brought by the AOP is particularly coupled to the essentiality and causality between the modules in the chain of events, as well as the AOP-Wiki platform allowing for broad collaborative efforts to gather and store information available for reuse and refinement.

In addition to iterative implementation of knowledge surrounding specific case study stressors, such as here covered by nanosized particles, the development of AOPs also benefits from efforts within other fields, even if challenges remain regarding how to adapt cross-field information to nanoparticles. For example, a recent effort to translate classical genotoxicity MoAs into the AOP framework can be expected to support refinement of the proposed AOP (Sasaki et al., 2020). The work was mainly focused on chemical-induced genotoxic MoAs, however, one of the preliminary AOPs describe the chain of KEs from "increased ROS leading to increases in gene mutations and chromosomal breaks/rearrangement" which is directly in line with KE1C, KE2, and KE3 in the putative AOP suggested here. In addition, the potential for genotoxic agents leaching from nanoparticles and leading to alternative parallel AOPs related to the formation of DNA adducts is supported by these efforts, and it provides a robust basis for further development and branching of AOP networks covering the various carcinogenic MoAs of nanoparticles. Finally, insight from the field of cancer research may provide clues through e.g., the 10 proposed key characteristics of carcinogens and the well-established hallmarks of cancer (Hanahan and Weinberg Robert, 2011; Smith et al., 2016).

Overall, the putative AOP, in its current form, supports systematic and structured integration and evaluation of mechanistic data derived from alternative ways of assessing primary and secondary genotoxicity, supporting safety assessments and prioritization of nanoparticles in need of

\section{REFERENCES}

Åkerlund, E., Cappellini, F., Di Bucchianico, S., Islam, S., Skoglund, S., Derr, R., et al. (2018), Genotoxic and mutagenic properties of $\mathrm{Ni}$ and $\mathrm{NiO}$ nanoparticles investigated by comet assay, $\gamma$-H2AX staining, Hprt mutation assay and ToxTracker reporter cell lines. Environ. Mol. Mutagen. 59, 211-222. doi: 10.1002/em.22163

Åkerlund, E., Islam, M. S., McCarrick, S., Alfaro-Moreno, E., and Karlsson, H. L. (2019). Inflammation and (secondary) genotoxicity of $\mathrm{Ni}$ and $\mathrm{NiO}$ nanoparticles. Nanotoxicology 13, 1060-1072. doi: 10.1080/17435390.2019.1640908

Amsen, D., de Visser, K. E., and Town, T. (2009). Approaches to determine expression of inflammatory cytokines. Methods Mol. Biol. 511, 107-142. doi: 10.1007/978-1-59745-447-6_5

Bayram, H., Ito, K., Issa, R., Ito, M., Sukkar, M., and Chung, K. F. (2006). Regulation of human lung epithelial cell numbers by diesel exhaust particles. Eur. Respir. J. 27, 705-713. doi: 10.1183/09031936.06.00012805 further testing (Nymark et al., 2020; Sasaki et al., 2020). The evidence gained from systematic application of data derived from these alternative testing approaches may provide insight into further research needs, as well as a robust basis needed for the shift toward safety assessment relying on non-animal methods-driven integrated testing strategies.

\section{DATA AVAILABILITY STATEMENT}

The original contributions presented in the study are included in the article, further inquiries can be directed to the corresponding author.

\section{AUTHOR CONTRIBUTIONS}

PN conceptualized the idea and wrote the first draft of the manuscript. HK, SH, and UV contributed to development of the putative AOP and to the writing of the manuscript. All authors contributed to the article and approved the submitted version.

\section{FUNDING}

$\mathrm{PN}, \mathrm{SH}$, and UV acknowledge the support by the PATROLS project, the European Union's Horizon 2020 Research and Innovation Programme under grant agreement No. 760813. UV acknowledges FFIKA, Focused Research Effort on Chemicals in the Working Environment from the Danish Government. $\mathrm{SH}$ acknowledges funding from the Genomics Research and Development Initiative of Health Canada (Ottawa, Canada). PN and $\mathrm{HK}$ acknowledge funds from the Swedish Fund for Research Without Animal Experiments [N2020-0005 (PN) and 2017-0041 $(\mathrm{HK})]$. HK further acknowledges funding from the Swedish Research Council for Environment, Agricultural Sciences and Spatial Planning (Formas, Grant No. 2017-00883).

\section{ACKNOWLEDGMENTS}

PN acknowledges the heads of the Institute of Environmental Medicine, Karolinska Institute, for support and an encouraging atmosphere.
Bendtsen, K. M., Gren, L., Malmborg, V. B., Shukla, P. C., Tunér, M., Essig, Y. J., et al. (2020). Particle characterization and toxicity in C57BL/6 mice following instillation of five different diesel exhaust particles designed to differ in physicochemical properties. Part Fibre Toxicol. 17:38. doi: 10.1186/s12989-020-00369-9

Braakhuis, H. M., Gosens, I., Heringa, M. B., Oomen, A. G., Vandebriel, R. J., Groenewold, M., et al. (2020). Mechanism of action of $\mathrm{TiO}(2)$ : recommendations to reduce uncertainties related to carcinogenic potential. Annu. Rev. Pharmacol. Toxicol. 61, 203-223. doi: 10.1146/annurev-pharmtox-101419-100049

Brightwell, J., Fouiliet, X., Cassano-Zoppi, A.-L., Bernstein, D., Crawley, F., Duchosal, F., et al. (1989). Tumours of the respiratory tract in rats and hamsters following chronic inhalation of engine exhaust emissions. J. Appl. Toxicol. 9, 23-31. doi: $10.1002 /$ jat.2550090106

Brunborg, G., Jackson, P., Shaposhnikov, S., Dahl, H., Azqueta, A., Collins, A. R., et al. (2014). High throughput sample processing and automated scoring. Front. Genet. 5:373. doi: 10.3389/fgene.2014.00373 
Buliaková, B., Mesárošová, M., Bábelová, A., Šelc, M., Némethová, V., Šebová, L., et al. (2017). Surface-modified magnetite nanoparticles act as aneugen-like spindle poison. Nanomedicine 13, 69-80. doi: 10.1016/j.nano.2016.08.027

Cappellini, F., Di Bucchianico, S., Karri, V., Latvala, S., Malmlöf, M., Kippler, M., et al. (2020). Dry generation of $\mathrm{CeO}_{(2)}$ nanoparticles and deposition onto a co-culture of A549 and THP-1 cells in air-liquid interface-dosimetry considerations and comparison to submerged exposure. Nanomaterials 10:618. doi: 10.3390/nano10040618

Catalán, J., Stockmann-Juvala, H., and Norppa, H. (2017). A theoretical approach for a weighted assessment of the mutagenic potential of nanomaterials. Nanotoxicology 11, 964-977. doi: 10.1080/17435390.2017.1382601

Chen, P., Kanehira, K., and Taniguchi, A. (2013). Role of toll-like receptors 3, 4 and 7 in cellular uptake and response to titanium dioxide nanoparticles. Sci. Technol. Adv. Mater. 14:015008. doi: 10.1088/1468-6996/14/1/015008

Chézeau, L., Sébillaud, S., Safar, R., Seidel, C., Dembélé, D., Lorcin, M., et al. (2018). Short- and long-term gene expression profiles induced by inhaled $\mathrm{TiO}_{2}$ nanostructured aerosol in rat lung. Toxicol. Appl. Pharmacol. 356, 54-64. doi: 10.1016/j.taap.2018.07.013

Coady, K., Browne, P., Embry, M., Hill, T., Leinala, E., Steeger, T., et al. (2019). When are adverse outcome pathways and associated assays "fit for purpose" for regulatory decision-making and management of chemicals? Integr. Environ. Assess. Manag. 15, 633-647. doi: 10.1002/ieam.4153

Collins, A. R., Annangi, B., Rubio, L., Marcos, R., Dorn, M., Merker, C., et al. (2017). High throughput toxicity screening and intracellular detection of nanomaterials. Wiley Interdiscip. Rev. Nanomed. Nanobiotechnol. 9:e1413. doi: $10.1002 /$ wnan. 1413

Corvi, R., and Madia, F. (2017). In vitro genotoxicity testing-can the performance be enhanced? Food Chem. Toxicol. 106, 600-608. doi: 10.1016/j.fct.2016.08.024

Costa, P. M., Gosens, I., Williams, A., Farcal, L., Pantano, D., Brown, D. M., et al. (2018). Transcriptional profiling reveals gene expression changes associated with inflammation and cell proliferation following short-term inhalation exposure to copper oxide nanoparticles. J. Appl. Toxicol. 38, 385-397. doi: 10.1002/jat.3548

Danielsen, P. H., Knudsen, K. B., Štrancar, J., Umek, P., Koklič, T., Garvas, M., et al. (2020). Effects of physicochemical properties of $\mathrm{TiO}_{2}$ nanomaterials for pulmonary inflammation, acute phase response and alveolar proteinosis in intratracheally exposed mice. Toxicol. Appl. Pharmacol. 386:114830. doi: 10.1016/j.taap.2019.114830

Decan, N., Wu, D., Williams, A., Bernatchez, S., Johnston, M., Hill, M., et al. (2016). Characterization of in vitro genotoxic, cytotoxic and transcriptomic responses following exposures to amorphous silica of different sizes. Mutat. Res. Genet. Toxicol. Environ. Mutagen 796, 8-22. doi: 10.1016/j.mrgentox.2015.11.011

Di Bucchianico, S., Cappellini, F., Le Bihanic, F., Zhang, Y., Dreij, K., and Karlsson, H. L. (2017). Genotoxicity of $\mathrm{TiO}_{2}$ nanoparticles assessed by mini-gel comet assay and micronucleus scoring with flow cytometry. Mutagenesis 32, 127-137. doi: 10.1093/mutage/gew030

Driscoll, K. E., Carter, J. M., Howard, B. W., Hassenbein, D. G., Pepelko, W., Baggs, R. B., et al. (1996). Pulmonary inflammatory, chemokine, and mutagenic responses in rats after subchronic inhalation of carbon black. Toxicol. Appl. Pharmacol. 136, 372-380. doi: 10.1006/taap.1996.0045

Dusinska, M., Mariussen, E., Rundén-Pran, E., Hudecova, A. M., Elje, E., Kazimirova, A., et al. (2019). In vitro approaches for assessing the genotoxicity of nanomaterials. Methods Mol. Biol. 1894, 83-122. doi: 10.1007/978-1-4939-8916-4_6

Dusinska, M., Tulinska, J., El Yamani, N., Kuricova, M., Liskova, A., Rollerova, E., et al. (2017). Immunotoxicity, genotoxicity and epigenetic toxicity of nanomaterials: new strategies for toxicity testing? Food Chem. Toxicol. 109, 797-811. doi: 10.1016/j.fct.2017.08.030

Ede, J. D., Lobaskin, V., Vogel, U., Lynch, I., Halappanavar, S., Doak, S. H., et al. (2020). Translating scientific advances in the AOP framework to decision making for nanomaterials. Nanomaterials 10:1229. doi: 10.3390/nano10061229

Edwards, S. W., Tan, Y.-M., Villeneuve, D. L., Meek, M. E., and McQueen, C. A. (2016). Adverse outcome pathways-organizing toxicological information to improve decision making. J. Pharmacol. Exp. Therapeut. 356, 170-181. doi: 10.1124/jpet.115.228239

Elder, A., Gelein, R., Finkelstein, J. N., Driscoll, K. E., Harkema, J., and Oberdörster, G. N. (2005). Effects of subchronically inhaled carbon black in three species.
I. Retention kinetics, lung inflammation, and histopathology. Toxicol. Sci. 88, 614-629. doi: 10.1093/toxsci/kfi327

Elespuru, R., Pfuhler, S., Aardema, M. J., Chen, T., Doak, S. H., Doherty, A., et al. (2018). Genotoxicity assessment of nanomaterials: recommendations on best practices, assays, and methods. Toxicol. Sci. 164, 391-416. doi: $10.1093 /$ toxsci/kfy100

Evans, S. J., Clift, M. J. D., Singh, N., Wills, J. W., Hondow, N., Wilkinson, T. S., et al. (2019a). In vitro detection of in vitro secondary mechanisms of genotoxicity induced by engineered nanomaterials. Part. Fibre Toxicol. 16:8. doi: 10.1186/s12989-019-0291-7

Evans, S. J., Gollapudi, B., Moore, M. M., and Doak, S. H. (2019b). Horizon scanning for novel and emerging in vitro mammalian cell mutagenicity test systems. Mutat. Res. Genet. Toxicol. Environ. Mutagen 847:403024. doi: 10.1016/j.mrgentox.2019.02.005

Fontana, C., Kirsch, A., Seidel, C., Marpeaux, L., Darne, C., Gaté, L., et al. (2017). In vitro cell transformation induced by synthetic amorphous silica nanoparticles. Mutat. Res. 823, 22-27. doi: 10.1016/j.mrgentox.2017.08.002

Gaté, L., Disdier, C., Cosnier, F., Gagnaire, F., Devoy, J., Saba, W., et al. (2017). Biopersistence and translocation to extrapulmonary organs of titanium dioxide nanoparticles after subacute inhalation exposure to aerosol in adult and elderly rats. Toxicol. Lett. 265, 61-69. doi: 10.1016/j.toxlet.2016.11.009

Ge, C., Peters, S., Olsson, A., Portengen, L., Schüz, J., Almansa, J., et al. (2020). Diesel engine exhaust exposure, smoking, and lung cancer subtype risks. a pooled exposure-response analysis of 14 case-control studies. Am. J. Respirat. Crit. Care Med. 202, 402-411. doi: 10.1164/rccm.201911-2101OC

Gerloff, K., Landesmann, B., Worth, A., Munn, S., Palosaari, T., and Whelan, M. (2017). The adverse outcome pathway approach in nanotoxicology. Comput. Toxicol. 1, 3-11. doi: 10.1016/j.comtox.2016.07.001

Gliga, A. R., De Loma, J., Di Bucchianico, S., Skoglund, S., Keshavan, S., Odnevall Wallinder, I., et al. (2020). Silver nanoparticles modulate lipopolysaccharidetriggered Toll-like receptor signaling in immune-competent human cell lines. Nanoscale Adv. 2, 648-658. doi: 10.1039/C9NA00721K

Gliga, A. R., Di Bucchianico, S., Lindvall, J., Fadeel, B., and Karlsson, H. L. (2018). RNA-sequencing reveals long-term effects of silver nanoparticles on human lung cells. Sci. Rep. 8:6668. doi: 10.1038/s41598-018-25085-5‘

Golbamaki, N., Rasulev, B., Cassano, A., Marchese Robinson, R. L., Benfenati, E., Leszczynski, J., et al. (2015). Genotoxicity of metal oxide nanomaterials: review of recent data and discussion of possible mechanisms. Nanoscale 7, 2154-2198. doi: $10.1039 / \mathrm{c} 4 \mathrm{nr} 06670 \mathrm{~g}$

Gomes, M., Teixeira, A. L., Coelho, A., Araújo, A., and Medeiros, R. (2014). "The role of inflammation in lung cancer," in Inflammation and Cancer, eds B. B. Aggarwal, B. Sung, and S. C. Gupta (Basel: Springer), p. 1-23. doi: 10.1007/978-3-0348-0837-8_1

Gren, L., Malmborg, V. B., Jacobsen, N. R., Shukla, P. C., Bendtsen, K. M., Eriksson, A. C., et al. (2020). Effect of renewable fuels and intake $\mathrm{O}_{2}$ concentration on diesel engine emission characteristics and Reactive Oxygen Species (ROS) formation. Atmosphere 11:641. https://www.mdpi.com/2073-4433/11/6/641/ htm10.3390/atmos11060641

Grosse, Y., Loomis, D., Guyton, K. Z., Lauby-Secretan, B., El Ghissassi, F., Bouvard, V., et al. (2014). Carcinogenicity of fluoro-edenite, silicon carbide fibres and whiskers, and carbon nanotubes. Lancet Oncol. 15, 1427-1428. doi: 10.1016/S1470-2045(14)71109-X

Halappanavar, S., Ede, J. D., Mahapatra, I., Krug, H. F., Kuempel, E. D., Lynch, I., et al. (2020a). A methodology for developing key events to advance nanomaterial-relevant adverse outcome pathways to inform risk assessment. Nanotoxicology 15, 289-310. doi: 10.1080/17435390.2020.1851419

Halappanavar, S., Ede, J. D., Shatkin, J. A., and Krug, H. F. (2019). A systematic process for identifying key events for advancing the development of nanomaterial relevant adverse outcome pathways. NanoImpact 15:100178. doi: 10.1016/j.impact.2019.100178

Halappanavar, S., Nymark, P., Krug, H. F., Clift, M. J. D., RothenRutishauser, B., and Vogel, U. (2021). Non-animal strategies for toxicity assessment of nanoscale materials: role of adverse outcome pathways in the selection of endpoints. Small 2021:2007628. doi: 10.1002/smll.2020 07628

Halappanavar, S., van den Brule, S., Nymark, P., Gaté, L., Seidel, C., Valentino, S., et al. (2020b). Adverse outcome pathways as a tool for the design of testing 
strategies to support the safety assessment of emerging advanced materials at the nanoscale. Part Fibre Toxicol. 17:16. doi: 10.1186/s12989-020-00344-4

Hanahan, D., and Weinberg Robert, A. (2011). Hallmarks of cancer: the next generation. Cell 144, 646-674. doi: 10.1016/j.cell.2011.02.013

Hashimoto, A. H., Amanuma, K., Hiyoshi, K., Sugawara, Y., Goto, S., Yanagisawa, R., et al. (2007). Mutations in the lungs of gpt delta transgenic mice following inhalation of diesel exhaust. Environ. Mol. Mutagen 48, 682-693. doi: 10.1002/em.20335

Heinrich, U., Fuhst, R., Rittinghausen, S., Creutzenberg, O., Bellmann, B., Koch, W., et al. (1995). Chronic inhalation exposure of wistar rats and two different strains of mice to diesel engine exhaust, carbon black, and titanium dioxide. Inhal. Toxicol. 7, 533-556. doi: 10.3109/08958379509015211

Hendriks, G., Derr, R. S., Misovic, B., Morolli, B., Calléja, F. M., and Vrieling, H. (2016). The Extended ToxTracker assay discriminates between induction of DNA damage, oxidative stress, and protein misfolding. Toxicol. Sci. 150, 190-203. doi: 10.1093/toxsci/kfv323

Hinderliter, P. M., Minard, K. R., Orr, G., Chrisler, W. B., Thrall, B. D., Pounds, J. G., et al. (2010). ISDD: a computational model of particle sedimentation, diffusion and target cell dosimetry for in vitro toxicity studies. Part Fibre Toxicol. 7:36. doi: 10.1186/1743-8977-7-36

Hougaard, K. S., Jackson, P., Jensen, K. A., Sloth, J. J., Löschner, K., Larsen, E. H., et al. (2010). Effects of prenatal exposure to surface-coated nanosized titanium dioxide (UV-Titan). A study in mice. Part Fibre Toxicol. 7:16. doi: 10.1186/1743-8977-7-16

Husain, M., Wu, D., Saber, A. T., Decan, N., Jacobsen, N. R., Williams, A., et al. (2015). Intratracheally instilled titanium dioxide nanoparticles translocate to heart and liver and activate complement cascade in the heart of C57BL/6 mice. Nanotoxicology 9, 1013-1022. doi: 10.3109/17435390.2014.996192

IARC (2006). Cobalt in Hard Metals and Cobalt Sulfate, Gallium Arsenide, Indium Phosphideand Vanadium Pentoxide. Monograph 86. Available online at: https:// monographs.iarc.fr/wp-content/uploads/2018/06/mono86.pdf

IARC (2010). Carbon Black, Titanium Dioxide, and Talc. Monograph 93. Available online at: https://publications.iarc.fr/111

IARC (2012a). Diesel and Gasoline Engine Exhausts and Some Nitroarenes. Monograph 105. Available online at: https://publications.iarc.fr/129

IARC (2012b). Review of Human Carcinogens (Package of 6 Volumes: A, B,C,D,E,F). Monograph 100. Available online at:: https://monographs.iarc.fr/wp-content/ uploads/2018/06/mono100C-10.pdf

IARC (2014). Some Nanomaterials and Some Fibres. Monograph 111. Available online at:: https://publications.iarc.fr/552

Institute IRS (2000). The relevance of the rat lung response to particle overload for human risk assessment: a workshop consensus report. Inhal. Toxicol. 12, 1-17. doi: 10.1080/08958370050164833

Jackson, P., Pedersen, L. M., Kyjovska, Z. O., Jacobsen, N. R., Saber, A. T., Hougaard, K. S., et al. (2013). Validation of freezing tissues and cells for analysis of DNA strand break levels by comet assay. Mutagenesis 28, 699-707. doi: 10.1093/mutage/get049

Jacobsen, N. R., Møller, P., Cohn, C. A., Loft, S., Vogel, U., and Wallin, H. (2008a). Diesel exhaust particles are mutagenic in FE1-MutaMouse lung epithelial cells. Mutat. Res. 641, 54-57. doi: 10.1016/j.mrfmmm.2008.03.001

Jacobsen, N. R., Pojana, G., White, P., Møller, P., Cohn, C. A., Smith Korsholm, K., et al. (2008b). Genotoxicity, cytotoxicity, and reactive oxygen species induced by single-walled carbon nanotubes and C60 fullerenes in the FE1Muta ${ }^{\mathrm{TM}}$ Mouse lung epithelial cells. Environ. Mol. Mutagen 49, 476-487. doi: $10.1002 / \mathrm{em} .20406$

Jacobsen, N. R., Saber, A. T., White, P., Møller, P., Pojana, G., Vogel, U., et al. (2007). Increased mutant frequency by carbon black, but not quartz, in the lacZ and cII transgenes of muta mouse lung epithelial cells. Environ. Mol. Mutagen 48, 451-461. doi: 10.1002/em.20300

Jeliazkova, N., Apostolova, M., Andreoli, C., Barone, F., Barrick, A., Battistelli, C., et al. (in press). Towards FAIR nanosafety data. Nat. Nanotechnol.

Jeliazkova, N., Chomenidis, C., Doganis, P., Fadeel, B., Grafström, R., Hardy, B., et al. (2015). The eNanoMapper database for nanomaterial safety information. Beilstein J. Nanotechnol. 6, 1609-1634. doi: 10.3762/bjnano.6.165

Karkossa, I., Bannuscher, A., Hellack, B., Wohlleben, W., Miruna, S., Dinischiotu, A., et al. (2021). Nanomaterials induce different levels of oxidative stress, depending on the used model system: Comparison of in vitro and in vivo effects. Res. Square [Preprint]. doi: 10.21203/rs.3.rs-57664/v2
Karlsson, H. L., Di Bucchianico, S., Collins, A. R., and Dusinska, M. (2015). Can the comet assay be used reliably to detect nanoparticle-induced genotoxicity? Environ. Mol. Mutagen 56, 82-96. doi: 10.1002/em.21933

Karlsson, H. L., Gliga, A. R., Calléja, F. M. G. R., Gonçalves, C. S. A. G., Wallinder, I. O., Vrieling, H., et al. (2014). Mechanism-based genotoxicity screening of metal oxide nanoparticles using the ToxTracker panel of reporter cell lines. Part. Fibre Toxicol. 11:41. doi: 10.1186/s12989-014-0041-9

Kohl, Y., Rundén-Pran, E., Mariussen, E., Hesler, M., El Yamani, N., Longhin, E. M., et al. (2020). Genotoxicity of nanomaterials: advanced in vitro models and high throughput methods for human hazard assessment-a review. Nanomaterials. 10:1911. doi: 10.3390/nano10101911

Kokot, H., Kokot, B., Sebastijanović, A., Voss, C., Podlipec, R., Zawilska, P., et al. (2020). Prediction of chronic inflammation for inhaled particles: the impact of material cycling and quarantining in the lung epithelium. Adv. Mater. 32:2003913. doi: 10.1002/adma.202003913

Kuempel, E., and Ruder, A. (2009). Identification of Research Needs to Resolve the Carcinogenicity of High-Priority IARC Carcinogens. IARC Technical Publication No. 42. Available online at: https://monographs.iarc.fr/wp-content/ uploads/2018/06/TR42-Full.pdf

Labib, S., Williams, A., Yauk, C. L., Nikota, J. K., Wallin, H., Vogel, U., et al. (2016). Nano-risk Science: application of toxicogenomics in an adverse outcome pathway framework for risk assessment of multi-walled carbon nanotubes. Part. Fibre Toxicol. 13:15. doi: 10.1186/s12989-016-0125-9

Lebedová, J., Hedberg, Y. S., Odnevall Wallinder, I., and Karlsson, H. L. (2018). Size-dependent genotoxicity of silver, gold and platinum nanoparticles studied using the mini-gel comet assay and micronucleus scoring with flow cytometry. Mutagenesis 33, 77-85. doi: 10.1093/mutage/gex027

Leist, M., Ghallab, A., Graepel, R., Marchan, R., Hassan, R., Bennekou, S. H., et al. (2017). Adverse outcome pathways: opportunities, limitations and open questions. Arch. Toxicol. 91, 3477-3505. doi: 10.1007/s00204-017-2045-3

Li, N., and Nel, A. E. (2006). The cellular impacts of diesel exhaust particles: beyond inflammation and death. Eur. Respir. J. 27, 667-668. doi: 10.1183/09031936.06.00025006

Liao, F., Chen, L., Liu, Y., Zhao, D., Peng, W., Wang, W., et al. (2019). The size-dependent genotoxic potentials of titanium dioxide nanoparticles to endothelial cells. Environ. Toxicol. 34, 1199-1207. doi: 10.1002/tox.22821

Ling, C., An, H., Li, L., Wang, J., Lu, T., Wang, H., et al. (2020). Genotoxicity evaluation of titanium dioxide nanoparticles in vitro: a systematic review of the literature and meta-analysis. Biol. Trace Elem. Res. 199, 2057-2076. doi: 10.1007/s12011-020-02311-8

Magdolenova, Z., Collins, A., Kumar, A., Dhawan, A., Stone, V., and Dusinska, M. (2014). Mechanisms of genotoxicity. A review of in vitro and in vivo studies with engineered nanoparticles. Nanotoxicology 8, 233-278. doi: $10.3109 / 17435390.2013 .773464$

Mauderly, J. L., Snipes, M. B., Barr, E. B., Belinsky, S. A., Bond, J. A., Brooks, A. L., et al. (1994). Pulmonary toxicity of inhaled diesel exhaust and carbon black in chronically exposed rats. Part I: neoplastic and nonneoplastic lung lesions. Res. Rep. Health Eff. Inst. 1-75, discussion 77-97.

McCarrick, S., Cappellini, F., Kessler, A., Moelijker, N., Derr, R., Hedberg, J., et al. (2020). ToxTracker reporter cell lines as a tool for mechanism-based (geno)toxicity screening of nanoparticles-metals, oxides and quantum dots. Nanomaterials 10:110. doi: 10.3390/nano100 10110

McCarrick, S., Wei, Z., Moelijker, N., Derr, R., Persson, K. A., Hendriks, G., et al. (2019). High variability in toxicity of welding fume nanoparticles from stainless steel in lung cells and reporter cell lines: the role of particle reactivity and solubility. Nanotoxicology 13, 1293-1309. doi: 10.1080/17435390.2019.16 50972

Medina-Reyes, E. I., Déciga-Alcaraz, A., Freyre-Fonseca, V., Delgado-Buenrostro, N. L., Flores-Flores, J. O., Gutiérrez-López, G. F., et al. (2015). Titanium dioxide nanoparticles induce an adaptive inflammatory response and invasion and proliferation of lung epithelial cells in chorioallantoic membrane. Environ. Res. 136, 424-434. doi: 10.1016/j.envres.2014.10.016

Medina-Reyes, E. I., Delgado-Buenrostro, N. L., Déciga-Alcaraz, A., FreyreFonseca, V., Flores-Flores, J. O., Hernández-Pando, R., et al. (2019). Titanium dioxide nanofibers induce angiogenic markers and genomic instability in lung cells leading to a highly dedifferentiated and fibrotic tumor formation in a xenograft model. Environ. Sci. Nano. 6, 286-304. doi: 10.1039/C8EN01078A 
Miller, F. J., Asgharian, B., Schroeter, J. D., and Price, O. (2016). Improvements and additions to the Multiple Path Particle Dosimetry model. J. Aerosol Sci. 99, 14-26. doi: 10.1016/j.jaerosci.2016.01.018

Nelson, B. C., Wright, C. W., Ibuki, Y., Moreno-Villanueva, M., Karlsson, H. L., Hendriks, G., et al. (2017). Emerging metrology for highthroughput nanomaterial genotoxicology. Mutagenesis 32, 215-232. doi: 10.1093/mutage/gew037

Nikota, J., Williams, A., Yauk, C. L., Wallin, H., Vogel, U., and Halappanavar, S. (2016). Meta-analysis of transcriptomic responses as a means to identify pulmonary disease outcomes for engineered nanomaterials. Part Fibre Toxicol. 13:25. doi: 10.1186/s12989-016-0137-5

Nymark, P., Bakker, M., Dekkers, S., Franken, R., Fransman, W., García-Bilbao, A., et al. (2020). Toward rigorous materials production: new approach methodologies have extensive potential to improve current safety assessment practices. Small 16:1904749. doi: 10.1002/smll.201904749

Nymark, P., Kohonen, P., Hongisto, V., and Grafström, R. (2018a). Toxic and genomic influences of inhaled nanomaterials as a basis for predicting adverse outcome. Ann. Am. Thorac. Soc. 15, S91-S97. doi: 10.1513/AnnalsATS.201706-478MG

Nymark, P., Rieswijk, L., Ehrhart, F., Jeliazkova, N., Tsiliki, G., Sarimveis, H., et al. (2018b). A data fusion pipeline for generating and enriching adverse outcome pathway descriptions. Toxicol. Sci. 162, 264-275. doi: 10.1093/toxsci/kfx252

Oberdörster, G., Oberdörster, E., and Oberdörster, J. (2005). Nanotoxicology: an emerging discipline evolving from studies of ultrafine particles. Environ. Health Perspect. 113, 823-839. doi: 10.1289/ehp.7339

Patel, S., Patel, P., and Bakshi, S. R. (2017). Titanium dioxide nanoparticles: an in vitro study of DNA binding, chromosome aberration assay, and comet assay. Cytotechnology 69, 245-263. doi: 10.1007/s10616-016-0054-3

Ponti, J., Sabbioni, E., Munaro, B., Broggi, F., Marmorato, P., Franchini, F., et al. (2009). Genotoxicity and morphological transformation induced by cobalt nanoparticles and cobalt chloride: an in vitro study in Balb/3T3 mouse fibroblasts. Mutagenesis 24, 439-445. doi: 10.1093/mutage/gep027

Riebeling, C., Wiemann, M., Schnekenburger, J., Kuhlbusch, T. A., Wohlleben, W., Luch, A., et al. (2016). A redox proteomics approach to investigate the mode of action of nanomaterials. Toxicol. Appl. Pharmacol. 299, 24-29. doi: 10.1016/j.taap.2016.01.019

Saber, A. T., Jacobsen, N. R., Jackson, P., Poulsen, S. S., Kyjovska, Z. O., Halappanavar, S., et al. (2014). Particle-induced pulmonary acute phase response may be the causal link between particle inhalation and cardiovascular disease. Wiley Interdiscip. Rev. Nanomed. Nanobiotechnol. 6, 517-531. doi: 10.1002/wnan.1279

Saber, A. T., Poulsen, S. S., Hadrup, N., Jacobsen, N. R., and Vogel, U. (2019). Commentary: the chronic inhalation study in rats for assessing lung cancer risk may be better than its reputation. Part Fibre Toxicol. 16:44. doi: 10.1186/s12989-019-0330-4

Saber, A. T., Poulsen, S. S., Hadrup, N., Jacobsen, N. R., and Vogel, U. (2020). A response to the letter to the editor by Driscoll et al. Part Fibre Toxicol. 17:32. doi: 10.1186/s12989-020-00364-0

Sasaki, J. C., Allemang, A., Bryce, S. M., Custer, L., Dearfield, K. L., Dietz, Y., et al. (2020). Application of the adverse outcome pathway framework to genotoxic modes of action. Environ. Mol. Mutagen. 61, 114-134. doi: 10.1002/em.22339

Schmid, O., and Stoeger, T. (2016). Surface area is the biologically most effective dose metric for acute nanoparticle toxicity in the lung. J. Aerosol. Sci. 99, 133-143. doi: 10.1016/j.jaerosci.2015.12.006

Shacter, E., and Weitzman, S. A. (2002). Chronic inflammation and cancer. Oncology 16, 217-226, 229; discussion 230-232.

Smith, M. T., Guyton, K. Z., Gibbons, C. F., Fritz, J. M., Portier, C. J., Rusyn, I., et al. (2016). Key Characteristics of Carcinogens as a Basis for Organizing Data on Mechanisms of Carcinogenesis. Environ. Health Perspect. 124, 713-721. doi: 10.1289/ehp.1509912

Taxell, P., and Santonen, T. (2016). Diesel Engine Exhaust. Occupational and Environmental Medicine. The Nordic Expert Group for Criteria Documentation of Health Risks from Chemicals and the Dutch Expert Committee on Occupational Safety. Available online at: https://gupea.ub.gu.se/bitstream/2077/ 44340/1/gupea_2077_44340_1.pdf

Teeguarden, J. G., Hinderliter, P. M., Orr, G., Thrall, B. D., and Pounds, J. G. (2007). Particokinetics in vitro: dosimetry considerations for in vitro nanoparticle toxicity assessments. Toxicol. Sci. 95, 300-312. doi: 10.1093/toxsci/kfl165

Tollefsen, K. E., Scholz, S., Cronin, M. T., Edwards, S. W., de Knecht, J., Crofton, K., et al. (2014). Applying Adverse Outcome Pathways (AOPs) to support Integrated Approaches to Testing and Assessment (IATA). Regul. Toxicol. Pharmacol. 70, 629-640. doi: 10.1016/j.yrtph.2014.09.009

Vales, G., Rubio, L., and Marcos, R. (2015). Long-term exposures to low doses of titanium dioxide nanoparticles induce cell transformation, but not genotoxic damage in BEAS-2B cells. Nanotoxicology 9, 568-578. doi: 10.3109/17435390.2014.957252

Vasilichin, V. A., Tsymbal, S. A., Fakhardo, A. F., Anastasova, E. I., Marchenko, A. S., Shtil, A. A., et al. (2020). Effects of metal oxide nanoparticles on Toll-like receptor mRNAs in human monocytes. Nanomaterials 10:127. doi: 10.3390/nano10010127

Vermeulen, R., Silverman, D. T., Garshick, E., Vlaanderen, J., Portengen, L., and Steenland, K. (2014). Exposure-response estimates for diesel engine exhaust and lung cancer mortality based on data from three occupational cohorts. Environ. Health Perspect. 122, 172-177. doi: 10.1289/ehp.1306880

Villeneuve, D. L., Crump, D., Garcia-Reyero, N., Hecker, M., Hutchinson, T. H., LaLone, C. A., et al. (2014). Adverse outcome pathway (AOP) development I: strategies and principles. Toxicol. Sci. 142, 312-320. doi: 10.1093/toxsci/kfu199

Villeneuve, D. L., Landesmann, B., Allavena, P., Ashley, N., Bal-Price, A., Corsini, E., et al. (2018). Representing the process of inflammation as key events in adverse outcome pathways. Toxicol. Sci. 163, 346-352. doi: $10.1093 /$ toxsci/kfy047

Vinken, M. (2019). Omics-based input and output in the development and use of adverse outcome pathways. Curr. Opin. Toxicol. 18, 8-12. doi: 10.1016/j.cotox.2019. 02.006

Warheit, D. B., Kreiling, R., and Levy, L. S. (2016). Relevance of the rat lung tumor response to particle overload for human risk assessment-update and interpretation of new data since ILSI 2000. Toxicology 374, 42-59. doi: 10.1016/j.tox.2016.11.013

Zhou, L., Li, P., Zhang, M., Han, B., Chu, C., Su, X., et al. (2020). Carbon black nanoparticles induce pulmonary fibrosis through NLRP3 inflammasome pathway modulated by miR-96 targeted FOXO3a. Chemosphere 241:125075. doi: 10.1016/j.chemosphere.2019.1 25075

Conflict of Interest: The authors declare that the research was conducted in the absence of any commercial or financial relationships that could be construed as a potential conflict of interest.

Copyright (c) 2021 Nymark, Karlsson, Halappanavar and Vogel. This is an openaccess article distributed under the terms of the Creative Commons Attribution License (CC BY). The use, distribution or reproduction in other forums is permitted, provided the original author(s) and the copyright owner(s) are credited and that the original publication in this journal is cited, in accordance with accepted academic practice. No use, distribution or reproduction is permitted which does not comply with these terms. 